\title{
OPEN Determining and quantifying the historical traces of spatial land arrangements in rural landscapes of Central and Eastern Europe
}

\author{
Barbara Prus $^{1 \bowtie}$, Małgorzata Dudzińska² \& Stanisław Bacior ${ }^{3}$
}

The article attempts to define and determine the intangible components of cultural heritage related to the spatial structure of land in a comprehensive way using computational methods. The components were quantified and a method of empirical evaluation of landscape durability was proposed for agricultural areas of significant cultural and historical value with an evident mosaic structure of fields, baulks, ponds, meadows, and forests. This method allows us to identify places more resistant to political transformation and those with greater cultural potential. The paper proposed an integrated approach to the measuring of the degree of preservation of spatial arrangements in the landscape based on a set of objects that describe the spatial land structure. The article classifies areas by the degree of preservation of rural spatial arrangements of land. The spatial analysis employed facilitated a synthetic quantification of the multi-criteria process. Three groups of factors were used: spatial assessment of land-cover type persistence $(u)$, agricultural land structure persistence $(w)$, and persistence of settlement buildings ( $\mathrm{z}$ ). The final results pinpointed areas in need of strategic intervention to sufficiently protect the rural cultural heritage, properly consider them in zoning planning, and ensure their sustainable development. The proposed tool can be used to monitor the degree of changes in the landscape layout structure when multiple time points are analysed as well.

Nearly 50\% of Europe's area is covered in agricultural land that builds characteristic agrarian landscapes. From the historical point of view, Europe has visually open and large-scale open-field landscapes and small-scale, enclosed 'bocage' landscapes'. The Institute for European Environmental Policy defines traditional agricultural landscapes as those that emerged from historical, meaning native, methods of land management, where traditional cultivation defined the dominant features of the cultural landscape. The characteristic feature of these agricultural systems is the distribution and mosaic arrangement of agricultural parcels characteristic of each region that determine how the landscape is perceived through its aesthetic qualities and even agrobiodiversity ${ }^{2}$.

Many European countries were transformed in the twentieth century. In Central and Eastern Europe, the transformations were rapid and intensive, such as changes in the landscape structure due to the collectivisation of land in the former Soviet Union and Eastern Block $\mathrm{k}^{1,2}$.

Research on historical agricultural landscapes indicates periods of relative stability entwined with times of transformation ${ }^{1}$.

European rural landscapes are being transformed due to climate change or changes in agriculture and public policy combined with urbanisation ${ }^{3}$. The changes affect the agricultural space ${ }^{4}$ and sociocultural identity of rural areas ${ }^{5}$. Every landscape has its unique history and individual features. In addition, landscape structures and field layouts evolve pressed by diverse factors ${ }^{6}$. Bürgi et al. grouped drivers of agricultural landscape change into five main forces $^{7}$ :

\footnotetext{
${ }^{1}$ Department of Land Management and Landscape Architecture, Faculty of Environmental Engineering and Land Surveying, University Agriculture, Balicka str. 253c, 30-149 Kraków, Poland. ${ }^{2}$ Institute of Geography and Land Management, Faculty of Geoengineering, University of Warmia and Mazury, Prawocheńskiego str. 15, 10-719 Olsztyn, Poland. ${ }^{3}$ Department of Agricultural Land Surveying, Cadastre and Photogrammetry, Faculty of Environmental Engineering and Land Surveying, University of Agriculture, Balicka str. 253a, 30-149 Kraków, Poland. ${ }^{\boxplus}$ email: b.prus@urk.edu.pl
} 
- socio-economic

- political, embodied in political agendas, laws, and politics

- technological, such as the effects of infrastructure expansion (including agricultural management and consolidation projects or the expansion of the railway transport in the nineteenth century)

- natural, consisting of settlement factors (soil parameters) and natural disturbances (from slides to climate change)

- cultural drivers as the most complex dimension of landscape-shaping factors.

Before the Second World War, Eastern and East-Central Europe faced significant political and economic changes ${ }^{8}$. Poland until 1989 was under the influence of nationalisation and centrally-planned economy. During this period environmental and landscape changes weren't so significant, which is due to, among other things, economic stagnation. After that date Poland transited from socialist planning to a market-oriented economy following the collapse of the USSR, which resulted in several structural changes ${ }^{9,10}$.

Although in the past, development focused on new geographical areas, today, previously developed areas are used increasingly often.

Cultural heritage, the patrimony of multiple generations is an important component of transformed space on which the progress exerts pressure ${ }^{11}$. Cultural as well as social and ecological heritage is traditionally regarded as a non-economic factor of spatial development ${ }^{12}$. However, treated as a resource and properly managed, it can be transformed into capital that can play an important role in sustainable development strategies, both at the local and national level. Cultural heritage as a particular type of resource of local communities has become an appreciated market asset ${ }^{13-16}$. It is an important part of the identity and driver of social integration ${ }^{17,18}$.

Agricultural landscapes can be considered cultural heritage. Even though their historic values differ, each can be assigned value and appeal, if only on a local scale. They can provide a foundation for cultural, educational, economic, or tourist activities and be a backbone for the local identity ${ }^{19}$. Researchers identify heritage resources even today with the progress of the work varying by site. While global cultural heritage assets have been identified to a large extent, regional ones in 'small homelands' call for further effort, particularly in agricultural areas. They should be identified immediately because the progress of civilisation might contribute to their irreversible loss. Excessive transformation can render an area not eligible for the cultural heritage list.

The awareness of the need for rational management of cultural heritage assets and their preservation for future generations has been discussed extensively ${ }^{20}$. Cultural heritage may not be directly perceivable in the physical landscape ${ }^{21}$. It is, therefore, impossible to capture its transformations without a spatial analysis. In many regions in Europe the landscape includes spatial arrangements of villages, the fields, meadows, rivers, lakes, hills, and forests around it as well as products of ages-long human impact on the environment. All these components can be arranged in various ways depending on the region in the world and topography. They should be protected, mainly by preserving their characteristics. With these resources identified, local governments gain new tools to perform their statutory obligations and implement solutions to stimulate the development in these areas, for example ${ }^{22}$. Identification of places where cultural heritage assets are located is vital for sustainable rural development. It stimulates more comprehensive growth of the areas. Hence the need to search for more effective ways of identifying cultural heritage assets and their quantitative analysis.

The knowledge about places where the characteristic historical spatial structure of land has been preserved is one of the inputs necessary to prevent the loss of culturally valuable agricultural landscapes.

The aim of the study is to determine the intangible i.e. to propose a new methodology for identifying and measuring the degree of persistence of historically formed spatial arrangements of rural areas not only in the agricultural landscapes of Poland but also in mosaic agricultural land found in Central and Eastern Europe. These are often long and narrow parcels where crops on arable land alternate with grassland, permanent crops, and stands of trees among fields, called complex cultivation patterns. Such management and agricultural use of land were actively influenced by human activity, parcel divisions, and legal mechanisms allowing inheritance by multiple people ${ }^{10}$. The proposed method is an integrated, quick, and precise quantitative analysis-based approach to assessing the degree of preservation of spatial arrangements in the landscape based on a measurable set of elements that describe the spatial land structure. The method can identify enclaves of the traditional landscape with unique traditional spatial arrangements of agricultural landscape structures that change the slowest or the least. Solymosi ${ }^{2}$ defined such places as cultural landscape hotspots. Identifying such sites is the starting point for further research, qualitative and quantitative both, on the preservation of cultural heritage.

The proposed typology of degrees of preservation and persistence of traditional spatial arrangements was based on a four-point scale. The taxonomic methods employed facilitated a synthetic quantification of the multicriteria process. Three groups of factors were used: spatial assessment of land-cover type persistence $(\boldsymbol{u})$, agricultural land structure persistence $(\boldsymbol{w})$, and persistence of settlement buildings $(\boldsymbol{z})$. The final results pinpointed areas in need of strategic intervention to sufficiently protect the rural cultural heritage, properly consider them in spatial planning policy, and ensure their sustainable development and protection.

\section{Theoretical background}

Agricultural landscape. The agricultural landscape has its characteristic features. Boundaries between parcels, baulks, stones, boundary mounds and trees, access roads, characteristic crops, and buffer strips make them unique. Agricultural operations are the primary actions that affect the dynamics of the agricultural landscape ${ }^{23}$. One can notice seasonal changes in the appearance of the landscape. Ploughing, sowing, harvest, hay cutting or silage collection; planting, thinning, or felling forest trees cause changes in colour and composition, dynamics in the landscape, often in a way characteristic of the place $^{24}$. 
Changes in the landscape are often perceived as a threat, negative evolution because changes today most often involve loss of diversity, coherence, and identity of existing landscapes ${ }^{25}$. New elements and structures are introduced that look the same regardless of the location.

Agricultural areas are particularly prone to changes caused by variations in demographics, farming (including new crops) intensified land use through innovative agricultural techniques and reforms ${ }^{26}$, or land abandonment resulting in forest succession, on the other hand.

Changes in the agrarian structure, such as consolidation of land, removal of baulks or stands of trees among fields, and disappearance of environmentally valuable land simplify the landscape and render it monotonous. Significant deforestation changes hydrographic conditions, endangering traditional extensive meadows and pastures, peat bogs, and ponds among fields.

Researchers often focus on the landscape and appreciate the need to classify and assess $i^{27}$. They propose the notion of landscape value and classify $\mathrm{it}^{28}$. The assessment of landscape, its structural complexity, relations and processes within it are best summarised in the notion of 'landscape structure'. Kondracki and Richling ${ }^{29}$ defined $^{2}$ landscape structure as a 'complex of components making up the landscape and their interrelations'. A dynamic landscape structure analysis involves the determination of relationships and dependencies among units (the horizontal dimension) and components (vertical dimension). Landscapes usually change through changes in their structural components ${ }^{30}$. Not many researchers looked into the opposite phenomenon, the persistence of the landscape $e^{7}$. Landscape persistence is the contradiction of landscape change. Landscape persistence is bound up with identity and landscape values ${ }^{25,31}$. It is often related to the notion of 'traditional landscape ${ }^{32-36}$. Persistence is also one of the attributes of cultural characteristic and valuation of the landscape ${ }^{21}$ as well as an important criterion for identifying traditional cultural landscapes ${ }^{37-40}$. In general, the literature describes traditional landscapes as those where farming consumes low external resources is dominated by relatively small (family) holdings. One of the main threats to the cultural value of these landscapes is related directly to the intensification of land use ${ }^{41}$.

The historical value of the traditional agricultural landscape is assessed based on its characteristic features: (a) the small-scale structure of the plot division is preserved; (b) the presence of original forms of anthropogenic relief (baulks); (c) unaltered land use; (d) employment of some traditional farming technologies ${ }^{38}$.

Tieskens et al. presented characterisation of European cultural landscapes based on the prevalence of three key dimensions of cultural landscapes: landscape structure, management intensity, value and meaning. They integrated and mapped the three dimensions into a continuous 'cultural landscape index' that facilitates a qualitative description of Europe's rural landscapes ${ }^{21}$. Jepsen et al. measured forest structure and its cultural value as related to its persistence understood as length of the period that the forest has been covering the area ${ }^{42}$. Agricultural landscape attributes that describe mosaic land cover, historical buildings, or the presence of livestock generally receive the highest value assessment ${ }^{43}$.

Characteristics of spatial arrangements in Polish agricultural areas. Eastern and south-eastern Poland, with its relatively extensive agriculture, offers particularly valuable agricultural landscapes exhibiting high biodiversity and rich genetic pools ${ }^{44}$. The landscapes of central, eastern, and southern Poland have small traditional holdings with mosaics of fields, baulks, ponds, meadows, and forests. The natural environment of most rural areas demonstrates an evident mosaic structure shaping the traditional landscape ${ }^{44}$.

The next landscape category is the heterogeneous, disharmonious landscape. These have large holdings practising intensive production (large fields without baulks, trees, or natural infrastructure) mixed with small, traditional holdings, small processing plants, or recreation and tourism sites.

Poland also has areas where the balance has been disturbed by human pressure, simplifying landscape structure and reducing biodiversity. A good example is numerous sites in north-western Poland where rural areas are considered mainly production zones with concentrated, large-area, intensive holdings, large areas of greenhouse or growing tunnel production, or intensive pig farming, while the economic growth is fuelled by the degradation of natural heritage ${ }^{45}$.

A mosaic farm structure typical of certain regions results in a striped or patchwork layouts of plots.

\section{Materials and methods}

Research organisation. To devise the methodology, the authors conducted empirical qualitative research to find a list of indices for spatial arrangement and quantitative research in order to measure them. This effort resulted in a classification of places with different degrees of spatial arrangement transformation.

To identify factors for assessing rural landscape layouts characteristic of land spatial arrangements of Central and Eastern Europe, the authors reviewed the literature, focusing on research techniques employed to evaluate landscape layouts, materials for analysis ${ }^{46-48}$, determination of indicators for assessing changes and persistence of the landscape and its structure ${ }^{40}$, and changes in land use. They also looked into the mosaic aspect of the agricultural landscape ${ }^{24}$.

The most common methods for assessing the variation in the spatial landscape structure are methods based on historical maps and photography analysis. The landscape structure is then estimated quantitatively with a set of landscape indicators ${ }^{49}$. The selection of characteristic variables for identifying landscape layouts is adjusted to the available area-covering spatial data at the given resolution ${ }^{50}$ and the objective of the analysis. According to Simensen ${ }^{50}$, 'Landscape metrics are focused on the description of the geometric and spatial properties of categorical map patterns and allow the characterisation and the investigation of land-use change processes'. The following indices are used most often: the total area, number of patches, perimeter-area ratio ${ }^{51-53}$, mean core area, Euclidean nearest-neighbour distance, the mean shape index, total edge ${ }^{46}$, landscape heterogeneity index, patch shape index, neighbour patch context, and the nearest neighbour distance index ${ }^{53}$. Other indices in the literature represent the general level of land-use change, like the binary change index ${ }^{54}$. Some researchers linked landscape 
structure to land ownership ${ }^{21,55,56}$. The shape of the field often results not only from the boundary and shape of the area of uniform land-use type but also from plot or parcel boundaries. Baulks, fencing, or lines of trees enrich the landscape and contribute to its increased mosaic. Note that the plot structure has the most significant impact on the seasonal appearance of the agricultural landscape. Baessler and $\mathrm{Klotz}^{49}$ and Stanfield ${ }^{56}$ looked into the aspect of ownership structure. Benoit ${ }^{23}$ pointed out the relationship between agricultural practices and landscape dynamics. The spatial structure of parcels is assessed based on parcel area, shape, and elongation indices, holding's parcel configuration ${ }^{57}$, or the patchwork (defined as a layout of plots or parcels separated by baulks etc.).

The research actions were planned and conducted to develop a methodology for identifying groups of areas exhibiting different degrees of preservation of spatial arrangements. This approach is vital for the preservation of cultural heritage assets that are under the pressure of such factors as urbanisation, globalisation, increasingly notorious natural disasters, or impact of the special pandemic circumstances today. The recognition methodology can be used as a tool for identifying such places to implement repair schemes or future local policies. A preserved historical layout of a locality is a testimony to how its long-gone residents shaped the place. Being historical development layouts, arrangements of buildings, complexes of houses, or hamlets are often listed as historical heritage in and of themselves. Research seldom focuses on the surroundings of these sites. No comprehensive research has been done on heritage assets to offer an integrated index representing the degree of preservation of the land structure, land-use types, and buildings.

Historical spatial arrangements, particularly rural ones, are often inconspicuous, and the local community (authorities) is unaware of their existence and location and fails to exploit them for local development. Cultural heritage is analysed on various levels of detail, but only a local analysis can capture historical spatial arrangement.

The proposed method can be applied to rural areas in Central and Eastern Europe but also in selected agricultural landscapes areas in the world where the spatial arrangement of land is similar. Thus it is not limited by the size, location, population, or economic status of the site. The methodology involves quasi-automatic data processing. One of its requirements is the availability of historical and modern maps for comparative analysis. It focuses on the use of geoinformatics to produce thematic maps with identified areas that are uniform in terms of the degree of preservation and persistence of historical layouts. Neither academic literature nor practical guides propose this approach to space assessment, especially regarding Poland.

The availability of data that describe the historical value of agricultural landscapes with the indicators from groups: spatial assessment of land cover type persistence, agricultural land structure persistence, and persistence of building location in space presented above is a technical limitation of the proposed method. The limitation is particularly apparent for maps that should present both land use structure and ownership structure. Moreover, the arrangement of the mosaics (historical and present state) should have similar characteristics as shown with the case study, that is, parcels shapes such as rectangles, rhombi, or other elongated figures. Such conditions can be identified mainly in areas where individuals own the land instead of state-controlled farms or associations, which cause changes in the agrarian structure by definition ${ }^{10}$.

A method for classifying the persistence of layouts. The analysis of cultural landscape change in Europe demonstrated that the preservation of traditional structures of the cultural landscape is affected by three main factors. These are isolation, difficult geographical situation, and nature of the local community. In-depth research demonstrated that the changes progressed faster in more developed areas closer to local centres, along roads. The trigger for the changes was a society with access to modern communications and infrastructure and additional funding, resulting in the 'industrialisation' of agriculture. Nevertheless, traditional agricultural structures and systems persisted in places where farming was a source of income or satisfied household consumption with surplus produce being sold, i.e. most often in the poorest families and ageing parts of the population ${ }^{2}$.

During the study it was assumed that rural landscapes in Central and Eastern Europe, the function of which did not change in a specific time, are more likely to contain cultural heritage assets, as researched i.e. Solymosi et al. ${ }^{2}$. She expected land-use transformation and changes in the possession structure to contribute to the loss of at least part of the cultural heritage potential. While aware of the fact that land use could change several times and return to the initial type over the analysed period, the authors considered such a possibility a marginal risk because the area has been rural $^{58}$.

The assessment involved three primary domains (see Fig. 1): (1) spatial assessment of land-cover type persistence; (2) spatial assessment of agricultural land structure persistence; and (3) structure of settlement buildings.

Spatial assessment of land-cover type persistence-Land-use structure index. Landscape persistence depends on the types of land cover that remain unaltered for some time ${ }^{40}$. Land-cover change (by land-cover types) was assessed using the land-use structure persistence equation ' $\boldsymbol{u}$ ' (1).

$$
\boldsymbol{u}=\sum_{A=1}^{n}\left(A_{t 0} \cap A_{t 1}\right)
$$

where $\boldsymbol{u}$ the land-use structure persistence index; $\boldsymbol{A}_{t 0}$ a selected land-use type: arable land, wasteland, grassland, forests, built-up areas in a start time $\boldsymbol{t}_{0} ; \boldsymbol{A}_{t 1}$ a selected land-use type in end time $\boldsymbol{t}_{1} ; \boldsymbol{n}$ the number of land-use types per spatial unit. This equation can group areas by the persistence of unchanged land use.

The analysed area was divided into spatial units-hexagons of 1.1652 ha in this case-where the degree of landuse persistence in start time $\boldsymbol{t}_{0}$ and end time $\boldsymbol{t}_{1}$ was assessed. The arrangement and size of spatial units should be chosen to suit characteristics of the area, its size, development, and spatial variation. 


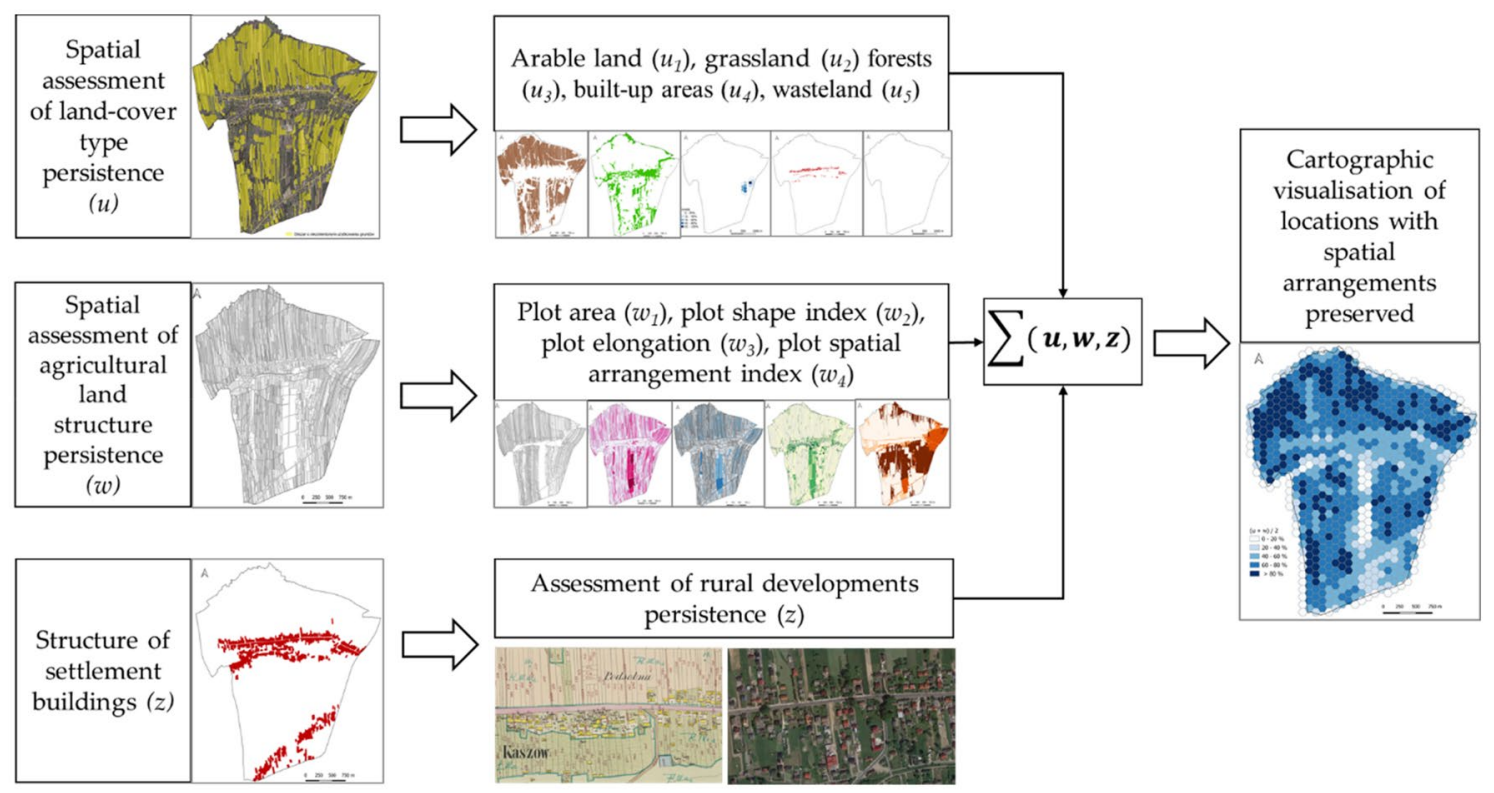

Figure 1. Research stages scheme.
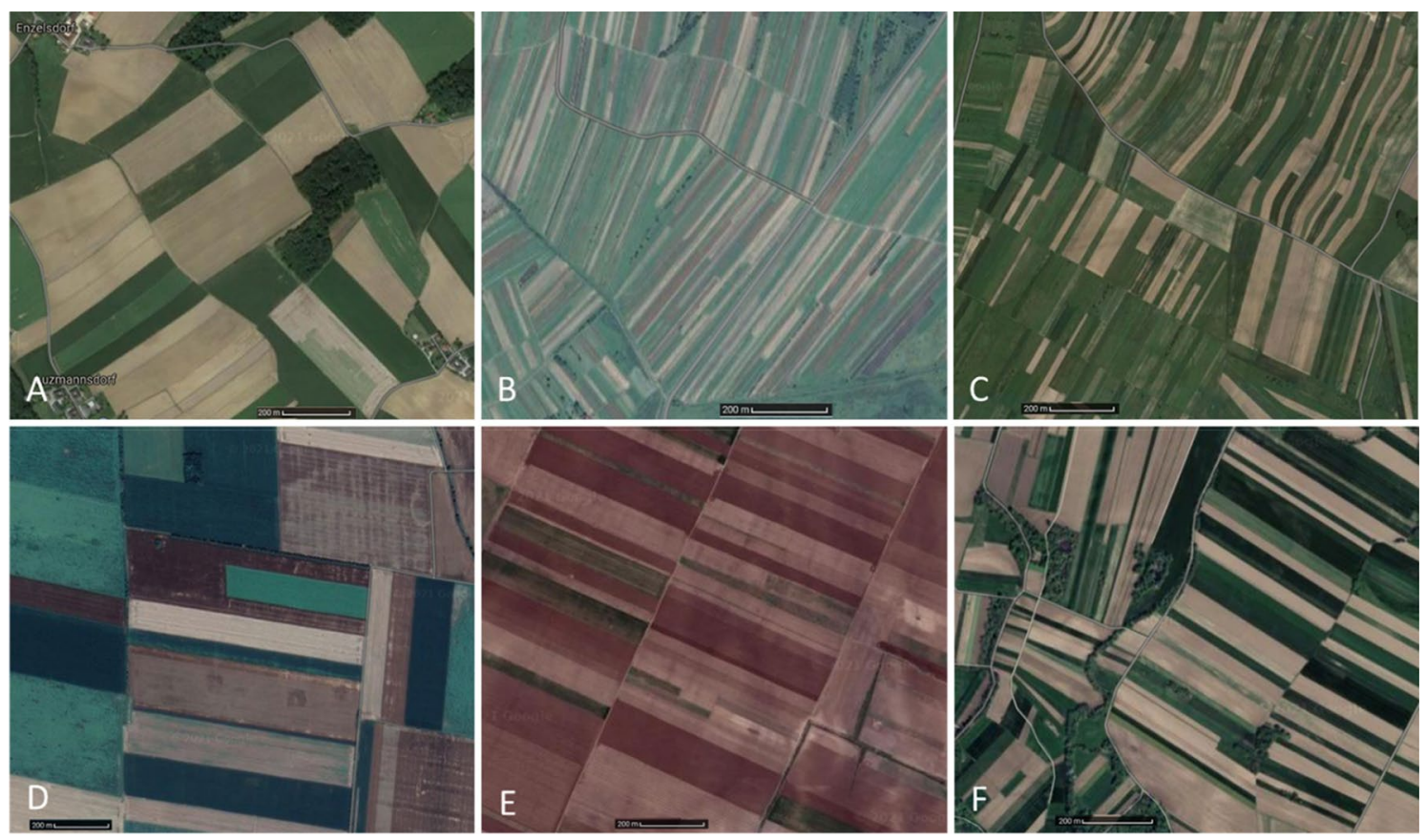

Figure 2. A local aspect of the spatial arrangement of fields (visual interpretation of $\boldsymbol{w}$ index) at the examples of East and Central Europe (A-Austria/Lutzmandorf; B-Ukraine/Hruszów; C-Poland/Sułoszowa; D-Hungary/ Csanadapaca; E-Romania/Ramnicelu; F-Slovenia/Gradisce). Source: google maps.

Spatial assessment of agricultural land structure persistence. It is not only the type of land use that shapes the spatial arrangement of a landscape structure. The shape of the field and plot also affects its appearance, particularly the dynamics of the agricultural landscape ${ }^{23}$. Baulks are the most clear boundaries in the landscape (see Fig. 2).

The image created by baulks is called a patchwork of fields. The number and layout of baulks determine the shapes and sizes of patches of land that make up the patchwork (mosaic structure). The mosaic can consist of small, irregular figures, large and regular ones, or long, narrow bands. The baulk is a natural or artificial separation of land patches resulting from multi-generational ownership arrangements. Therefore, the authors considered it necessary to assess the persistence of land layouts in the area. For the research objective, it is the layout of parcels in space, not their size that is important. Hence the importance of comparison of land structure distribution. The statistical procedure was based on total ordering and classification of spatial units (such 
as hexagons). The possession conditions at start time $\boldsymbol{t}_{\mathbf{0}}$ covered land parcels that have been transformed into plots at end time $\boldsymbol{t}_{1}$.

The proposed method includes four stages.

Stage $I$ is a determination of component indices for land structure assessment. The variables were selected also in four steps. Based on in-depth analysis of literature on land structure assessment ${ }^{57,59,60}$, the authors first selected a set of features that best described the investigated phenomenon. The selection was determined by the measurability, availability, and completeness. Land structure was assessed using plot area $w_{1}$, plot shape index $\boldsymbol{w}_{2}$, field layout assessment index was derived from the component indices, index of plot elongation $\boldsymbol{w}_{3}$, and mean plot axis angle $\boldsymbol{w}_{4}$.

Stage II. In the second stage the component indices $\left(\boldsymbol{w}_{1}\right.$ to $\left.\boldsymbol{w}_{4}\right)$ for a start time $\boldsymbol{t}_{\mathbf{0}}$ and end time $\boldsymbol{t}_{1}$ were calculated. This way, spatial units could be total ordered into categories with similar values of the indices. In this case, the spatial units were hexagons.

The $\boldsymbol{w}_{\mathbf{1}}$ index was calculated in hectares directly from the polygon coordinates. Shape index $\boldsymbol{w}_{\mathbf{2}}$ was calculated using Eq. (2) originally developed for representing landscape fragmentation ${ }^{61,62:}$

$$
w 2=\frac{p i}{2 \sqrt{\pi w 1}}
$$

where $\boldsymbol{p}_{\boldsymbol{i}}$-the plot perimeter, $\boldsymbol{w}_{\mathbf{1}}$-the plot area.

The $\boldsymbol{w}_{3}$ index-the plot elongation was calculated using formula (3):

$$
w 3=\frac{a}{b}
$$

where $\boldsymbol{a}$-the shorter side of the plot; $\boldsymbol{b}$-the longer side of the plot. The larger $\boldsymbol{w}_{3}$, the more elongated the parcel shape.

The $\boldsymbol{w}_{\mathbf{4}}$ index-the main axis angle is assumed to be the main angle of the polygon. The longest side of the polygon is considered its main axis. It indicates the direction in which plots are positioned in space. This operation used the Calculate Polygon Main Angle tool in ArcGIS.

Stage III. At the third stage, the authors compared the results for start time $\boldsymbol{t}_{\mathbf{0}}$ and the end time $\boldsymbol{t}_{\mathbf{1}}$ using intersection (4):

$$
W=\sum_{w=1}^{m}\left(W_{t 0} \cap W_{t 1}\right)
$$

where $\boldsymbol{W}$ land structure persistence index; $\boldsymbol{W}_{t 0}$ component indices for land structure assessment (i.e. area, shape, elongation, and angle) in start time $\boldsymbol{t}_{\mathbf{0}} ; \boldsymbol{W}_{t 1}$ component indices for land structure assessment in end time $\boldsymbol{t}_{\mathbf{1}} ; \boldsymbol{m}$ the number of component indices used. The analysis was performed using a five-point scale ( $\left.20 \% \mathrm{steps}\right)$. Stage IV. The goal of this step was to construct an integrated index for spatial assessment of the persistence of agricultural land structure. Homogeneous objects were classified with Eq. (5):

$$
w=\frac{1}{n} \sum_{i=1}^{m} W i
$$

where $\boldsymbol{w}$ the integrated index for spatial assessment of persistence of agricultural land structure; $\boldsymbol{W}_{\boldsymbol{i}}$ component indices; $\boldsymbol{m}$ the number of component indices.

Spatial assessment of settlement buildings. The assessment of rural development involved the determination of an index of persistence of building distribution (Eq. 6) for two points in start time $\boldsymbol{t}_{\mathbf{0}}$ and end time $\boldsymbol{t}_{\mathbf{1}}$.

$$
Z=\sum_{B=1}^{l}\left(B_{t 0} \cap B_{t 1}\right)
$$

where $\boldsymbol{B}_{\boldsymbol{t} \boldsymbol{0}}$ buildings in start time $\boldsymbol{t}_{\boldsymbol{0}} ; \boldsymbol{B}_{\boldsymbol{t} 1}$ buildings in time $\boldsymbol{t}_{1} ; \boldsymbol{Z}$ building location persistence index; $l$ the number of buildings in the area.

This equation can identify buildings that are located in similar places (partially consistent locations) in time $t_{0}$ and $t_{1}$.

Materials. Maps are widely used in quantitative analyses of land cover changes in Europe and analysis of the spatial structure of land ${ }^{63}$. They help reach into the history, providing sufficient precision for small- and medium-scale research ${ }^{64,65}$. Austrian cadastral maps are generally considered reliable, detailed, and useful for assessing landscape structure in the former territory of the Austro-Hungarian Empire ${ }^{66}$.

The main sources for reconstructing historical spatial composition of a rural area according to its history were maps created when surveys for the second Galician cadastre called the Franciscan cadastre were conducted in the former Austro-Hungarian Empire (which covered the entire or partial area of twelve Central-European countries, including Austria, Bosnia and Herzegovina, Czechia, Croatia, Hungary, Italy, Poland, Serbia, Slovakia, Slovenia, and Ukraine) and an orthophoto with a Database of Topographic Objects, DTO10k overlay for 2016. The DTO10k includes units of administrative division, transport network, buildings (their location and functions), 


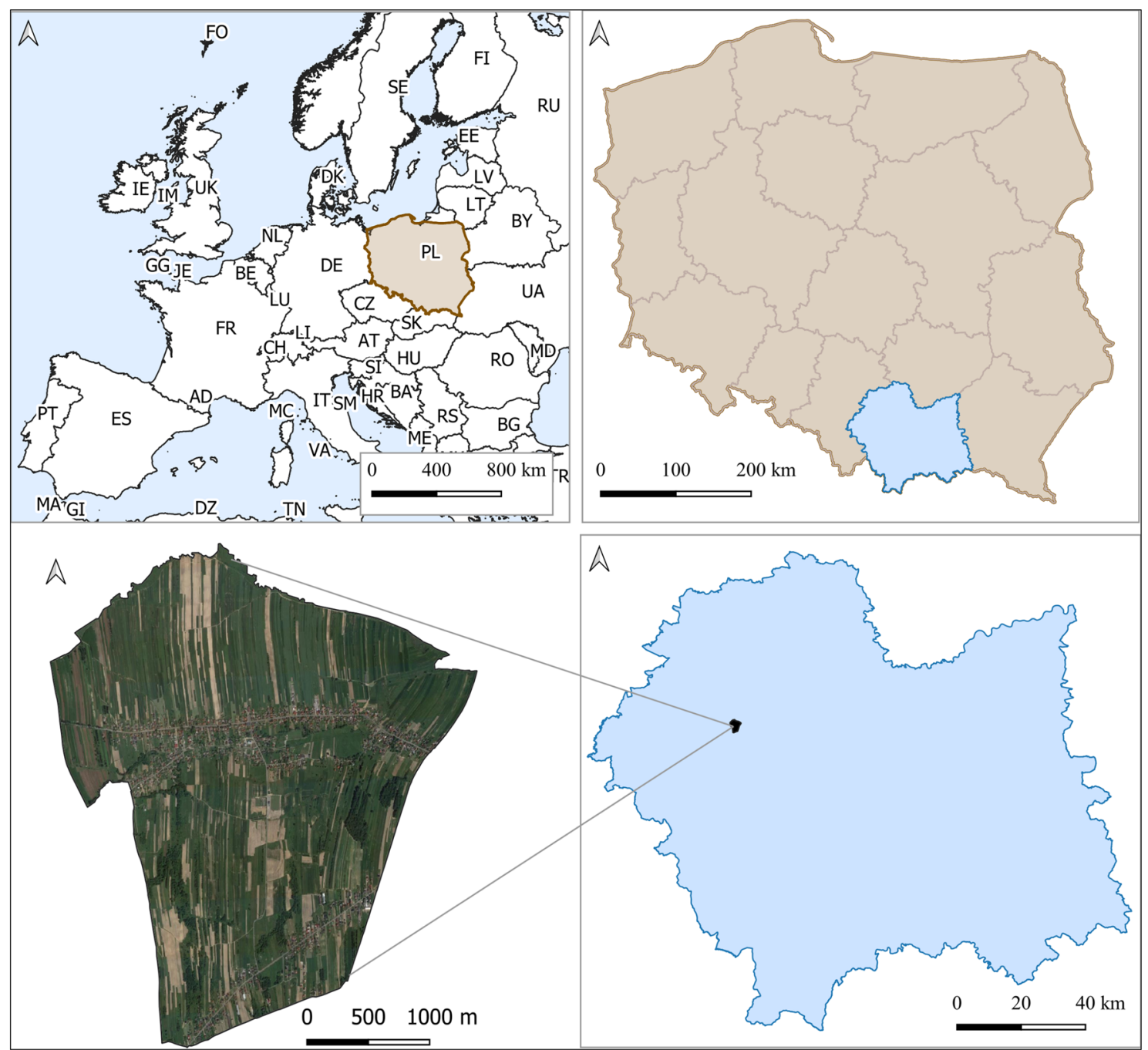

Figure 3. Location of the study area, Kaszów coordinates 552106, 241411-EPSG 2180.

and complexes of land-use types. The research was carried out in QGIS and ARCGIS using geoprocessing tools as well as data management tools (a combination of attributes according to the location).

The Franciscan Cadastre maps were drawn using a rectangular arrangement of 1 Austrian mile square sheets, so-called triangulation map sheets ${ }^{67,68}$. A smaller scale allowed more details to be recorded. Information provided by the map includes the type of development, layout of development, plot boundaries and numbers, water bodies, vegetation (including its arrangement and forms), spatial arrangements (spatial layouts, links, spatial relations, sequences), composition (such as sightlines, landmarks, emphasis, vantage points and view obstructions, and sets of vantage points). Such information helps analyse the type of development layout and its basic modules, parcellation, plot size with their typical shape and dimensions, width and positioning of buildings relative to streets, layout and density of buildings on a plot and arrangement of fields. They record past boundaries and subdivisions ${ }^{68}$. The map content is certainly abundant and precise. Patterns and colours make up about 150 legend items ${ }^{69}$.

The analysis required a prior development of a key for interpreting map labels and photointerpretation keys. Taking into account the objective of the study, the quality of the Austrian cadastral maps (scale 1:2880), the accuracy of terrain representation on orthophotos, and land-use structure form the DTO10k, the authors had to modify the photointerpretation keys. The modification concerned mostly grassland (recently not divided into meadows and pastures) and built-up areas. Seven land-cover categories for rural areas were identified: arable land, grassland, wasteland, built-up areas, water bodies, roads, and forests.

Study area. The authors are perfectly familiar with the typical agricultural village of Kaszów, located in the south part of Poland, Europe in Małopolska (Fig. 3), subjected to the investigation selected to measure the degree of preservation of historical rural layouts. This way, it was easier to verify the results and assess the soundness of the approach.

Kaszów is a village established around the twelfth century. To this day, the village has been characterised by a linear housing pattern. In 1869, there were 250 peasant cottages in Kaszów, inhabited by 1,401 people. Over the 
following years, the population grew steadily to reach 1,523 inhabitants as early as 1880 . The place occupied an area of 1,446 Austrian morgens ( 1 Austrian morgen $=0.56 \mathrm{ha}$ ). The land use structure of that time was dominated by arable land (922 morgens), pastures (277 morgens), meadows and gardens (227 morgens), and only a little forest of 20 morgens.

The settlement was located on the transit route, the high road from Kraków to Silesia. It remains a linear village to this day ${ }^{27}$.

\section{Results}

Spatial assessment of land-cover type persistence (U). After an assessment of the general trend in land-cover change from 1848 to 2016, it is evident that the area has remained agricultural in nature. Areas of land-use types in land cover changed only in some parts of the village. In 1848, the area of agricultural land was $95.6 \%$, while today it is $76.8 \%$ (arable land and grassland). The difference in agricultural land area between the mid-nineteenth century and today (2016) is $18.8 \%$. The dominant land-use type is arable land, which occupies $62.5 \%$ of the area, while in the nineteenth century, it was $61.8 \%$. The second land-use type is grassland (meadows and pastures). The spatial assessment of land-cover type persistence (u) in Kaszów demonstrated a high level of preservation of the historical structure. As much as $33.8 \%$ of the area (262 hexagons) exhibited a very high level of consistency of historical and current use, while $20 \%$ of the area exhibits a high level (Fig. 4, compare with Fig. 7G). Only $13 \%$ of the area has a very low consistency of less than $20 \%$. The northern part of the area demonstrated the highest persistence of the land-use structure.

Spatial assessment of agricultural land structure persistence. Spatial variation in component indices of the agricultural land structure (plot area $\left(\boldsymbol{w}_{1}\right)$, plot shape $\left(\boldsymbol{w}_{2}\right)$, plot elongation $\left(\boldsymbol{w}_{3}\right)$, and mean plot axis angle $\left(\boldsymbol{w}_{4}\right)$ were obtained. The spatial diversification of the component indices was divided into four classes based on national and regional statistics and literature (Fig. 5, 6).

Areas of plots and parcels of land $\left(\boldsymbol{w}_{1}\right)$. Parcels in Kaszów were rather small with the mean value of 0.1742 ha and coefficient of variation 4.9 in 1848 . Today, the mean plot area remains small. It is 0.2136 ha with the coefficient of variation of only 1.5. In 1848, Kaszów was subdivided into 3,902 parcels with $91 \%$ of them smaller than 0.5 ha. Now, Kaszów has 4,399 plots, and $91 \%$ of them are not larger than 0.5 ha (Fig. 7A).

Shape index $\left(\boldsymbol{w}_{2}\right)$. The mean value of the shape index for Kaszów in 2016 r. was 0.019 , in 1848, 0.017. In 1848, $91.7 \%$ of the parcels exhibited $\boldsymbol{w}_{2}$ index up to 0.05 , which is similar to today's share of $91.5 \%$. About $8 \%$ of the plots had $w_{2}$ ranging from 0.05 to 0.20 in time $t_{0}$ and $t_{1}$ (Fig. $7 \mathrm{~B}$ ).

Plot elongation index $\left(\boldsymbol{w}_{3}\right)$. The plots in Kaszów are usually rather elongated, narrow quadrangles (rectangles, trapeziums). The mean plot elongation in 2016 was 0.154 , while in $1848,0.221$. In $1848,67 \%$ of the parcels were elongated up to 0.24 and $20 \%$ from 0.24 to 0.48 . In 2016 , elongation of up to 0.24 was exhibited by $81 \%$ of plots, while $12 \%$ were elongated from 0.24 to 0.48 (Fig. 7C).

Main plot axis angle $\left(\boldsymbol{w}_{4}\right)$. As many as $62 \%$ of plots in Kaszów exhibited a mean plot axis angle located in the $-90^{\circ}$ to $-45^{\circ}$ quadrant in 2016 . This value was high in 1848 as well, $56 \%$. The smallest number of plots was found in the quadrant ranging from $-45^{\circ}$ to $0^{\circ}: 5.5 \%$ in 1848 and $2 \%$ in 2016 (Fig. 7D).

The variation in the persistence of land structure component indices $\left(\boldsymbol{w}_{\mathbf{1}}-\boldsymbol{w}_{\mathbf{4}}\right)$ in each index was divided into five intervals (20\% each).

The most persistent one was index $\boldsymbol{w}_{4}$, main plot axis angle. Its spatial persistence is very high for $54.7 \%$ of the area. This result demonstrates that directions of plots are the same for both time points for most of the area. Another index with a high level of persistence was plot elongation $\left(\boldsymbol{w}_{3}\right)$. Very high and high persistence was found for $58.1 \%$ of the area. The area still has plots with similar characteristics, including elongation. The two other features, area and shape, did not exhibit high persistence. Only $16.1 \%$ of the area had very high field area persistence. It could suggest a significant number of plot subdivisions over the period. In 1848, the village had 3,902 parcels, while today the number is 4,399 . Subdivisions of plots changed their shapes, which is apparent from the shape index, $\boldsymbol{w}_{2}$. The area exhibits a rather low spatial persistence of the index. In accordance with the methodology, the integrated index is the mean of the component indices (Fig. 7E). The spatial assessment of the persistence of agricultural land structure $(\boldsymbol{w})$ demonstrated that only $12 \%$ of the area exhibited land structure that was very similar to the same forms in the past. The largest share, $43 \%$ of the area exhibited high persistence. Very low and low persistence of the land structure was found for $12 \%$ and $8 \%$ of the area, respectively. The medium persistence was found for $25 \%$ of the area. The spatial distribution of the land structure persistence is shown in Fig. 7F. The results show that the land structure of the area changed to a larger or lesser degree. Some plots were subdivided, which increased their number and the mosaic character of the area. Nevertheless, the subdivisions had a moderate impact on the spatial arrangement of the plots because they most often involved dividing the plot perpendicularly to the longest boundary.

Figure 8 shows maps with spatial variation in buildings from 1848 to 2016 . With Eq. (6), the authors identified buildings that have overlapping parts for the two time points. They pinpointed potential objects that could be dated back to 1848 . The analysis of the results and a site visit yielded eight objects in the village that could potentially be dated back to 1848 .

The aggregation of indices $\boldsymbol{u}, \boldsymbol{w}$, and $\boldsymbol{z}$ yielded the spatial distribution of the persistence of layouts in Kaszów (Fig. $7 \mathrm{H}$ ). The spatial assessment of layout persistence demonstrated that only $4 \%$ of the area exhibited layouts 


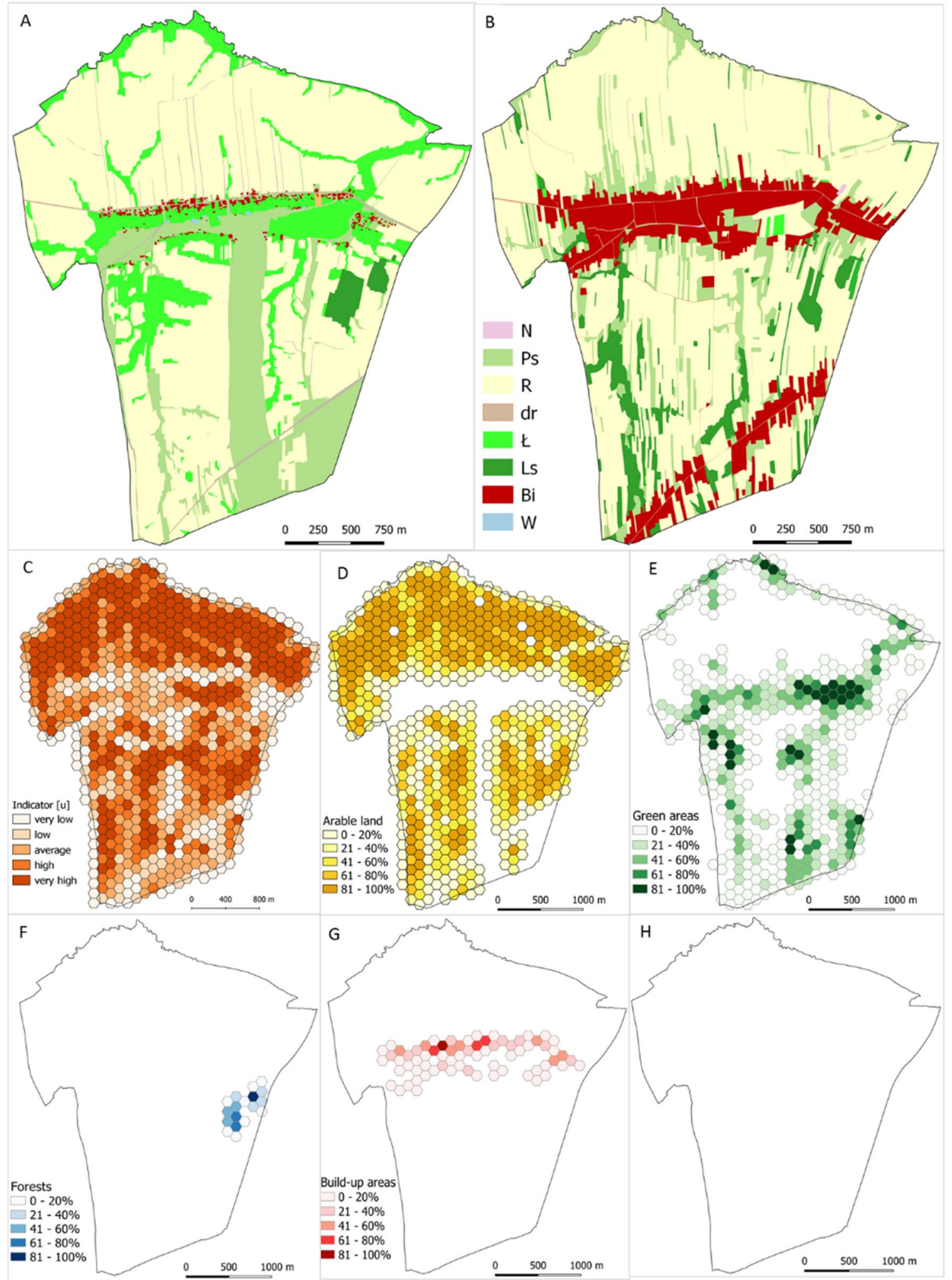

Figure 4. Stages of the spatial assessment of land-use (land-cover types) structure persistence analysis. (A) Land use structure in the start time $\boldsymbol{t}_{0}$; (B) Land use structure in the end time $\boldsymbol{t}_{1}$; (C) Land-use structure persistence index $\boldsymbol{u}$ spatial distribution; (D) persistence of arable land; (E) persistence of grassland; (F) persistence of forests; $(\mathbf{G})$ persistence of built-up areas; $(\mathbf{H})$ persistence of wasteland. 

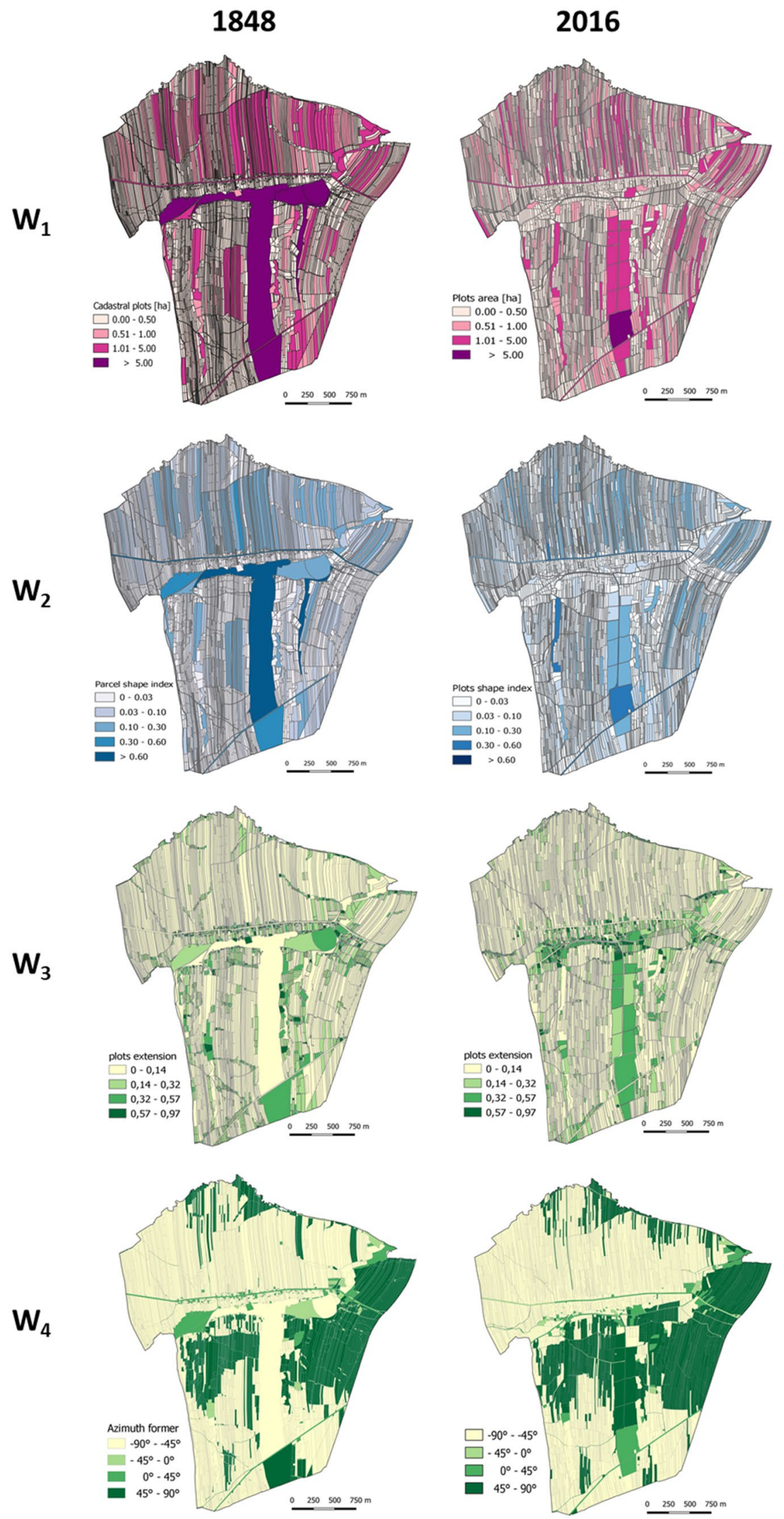

Figure 5. Spatial distribution of component indices. 

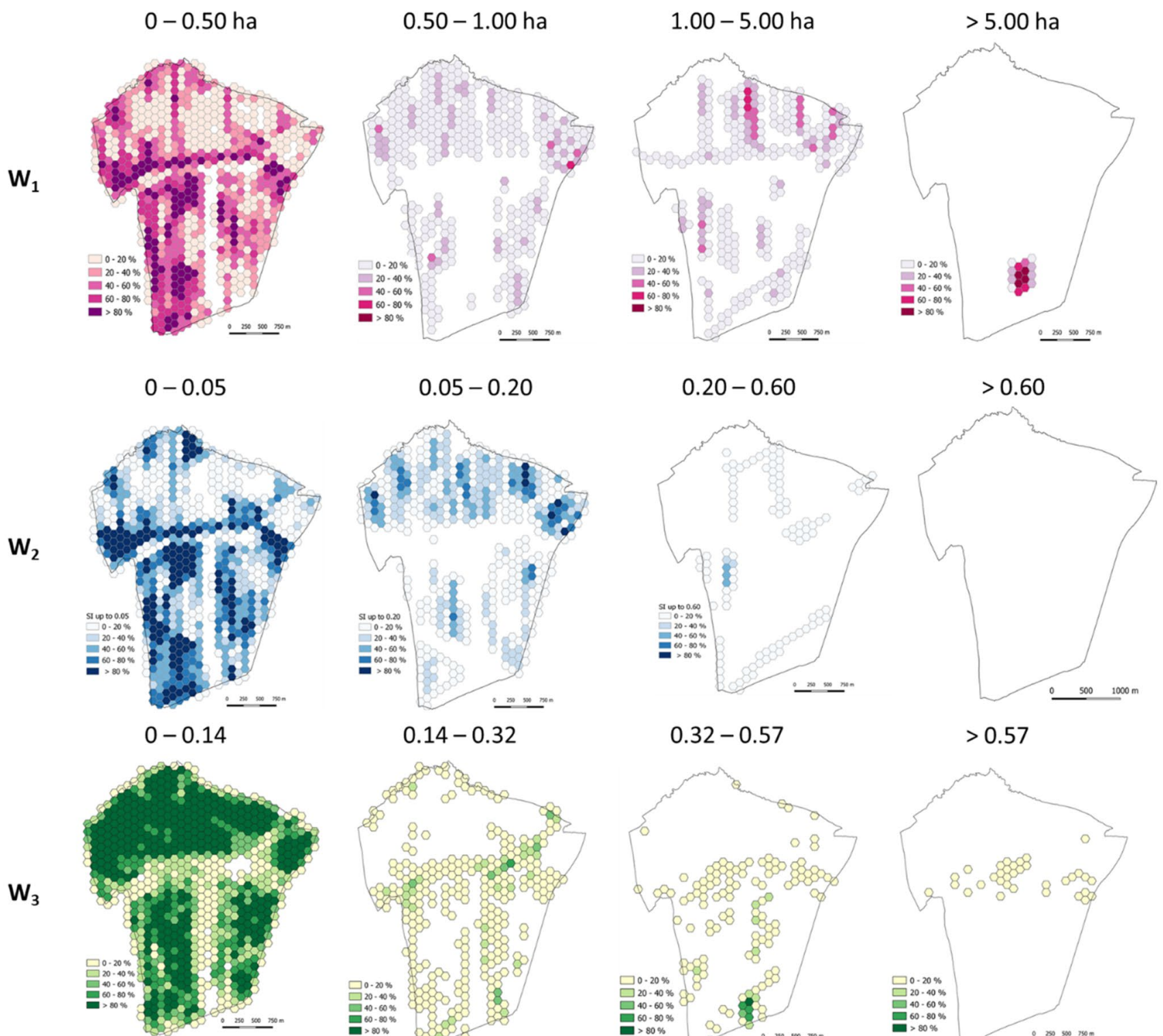

$$
0.32-0.57
$$
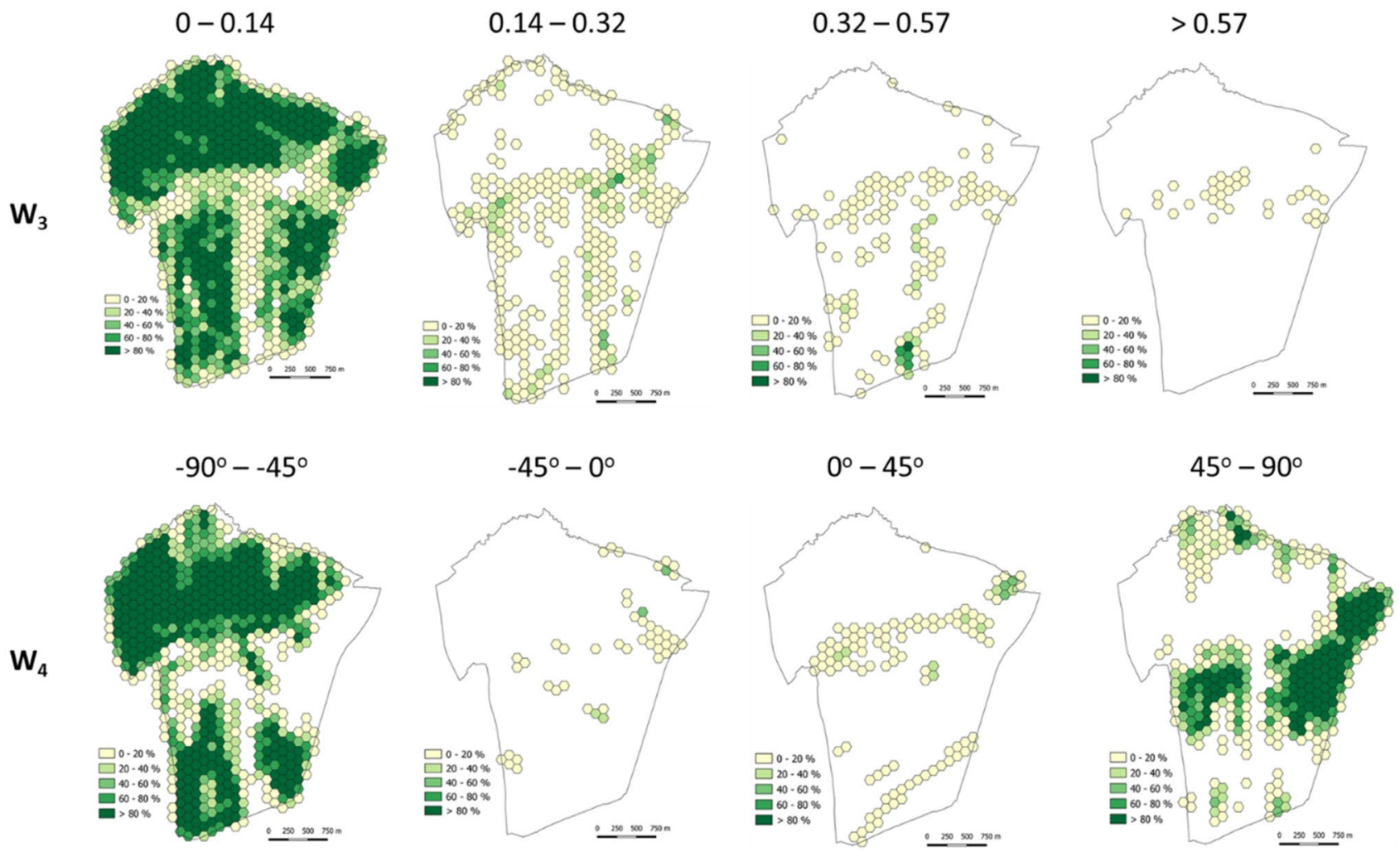

Figure 6. The variation in component indices by variable category.

very similar in the two time points. The largest share, $42 \%$ of the area exhibited high persistence. Very low and low persistence of the layout structure was found for $11 \%$ and $15 \%$ of the area, respectively. The medium persistence was found for $28 \%$ of the area. 

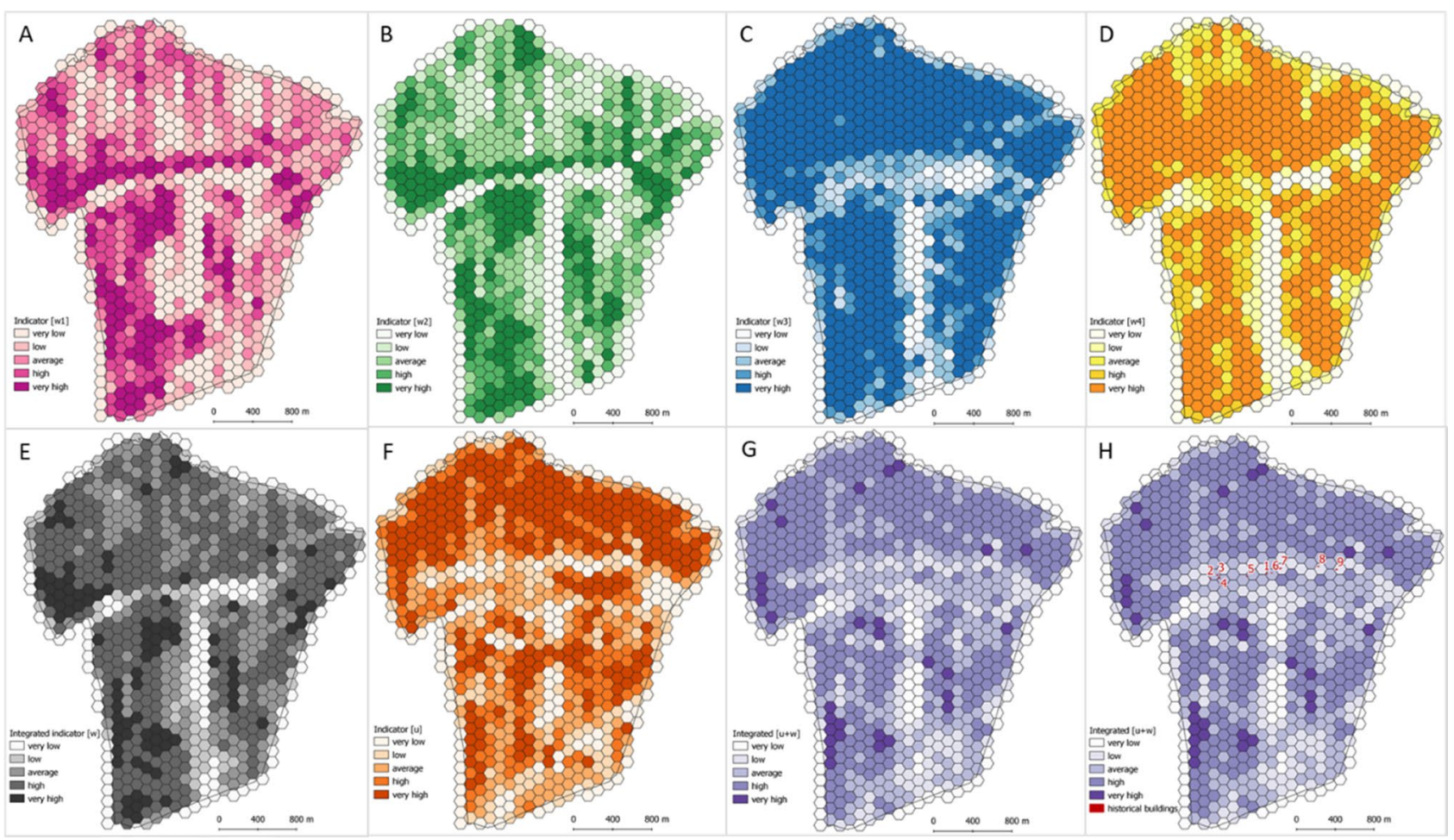

Figure 7. Spatial variation in the persistence of component indices. (A) $w_{1}$ index; (B) $w_{2} ;(\mathrm{C}) \boldsymbol{w}_{3} ;$ (D) $\boldsymbol{w}_{4}$, (E) land structure persistence integrated index $(\boldsymbol{w}) ;(\mathbf{F})$ Land-use structure persistence index $\boldsymbol{u} ;(\mathbf{G})$ land structure persistence integrated index $(\boldsymbol{u}+\boldsymbol{w}),(\mathbf{H})$ persistence phenomenon integrated index $(\boldsymbol{u}+\boldsymbol{w}+\boldsymbol{z})$.
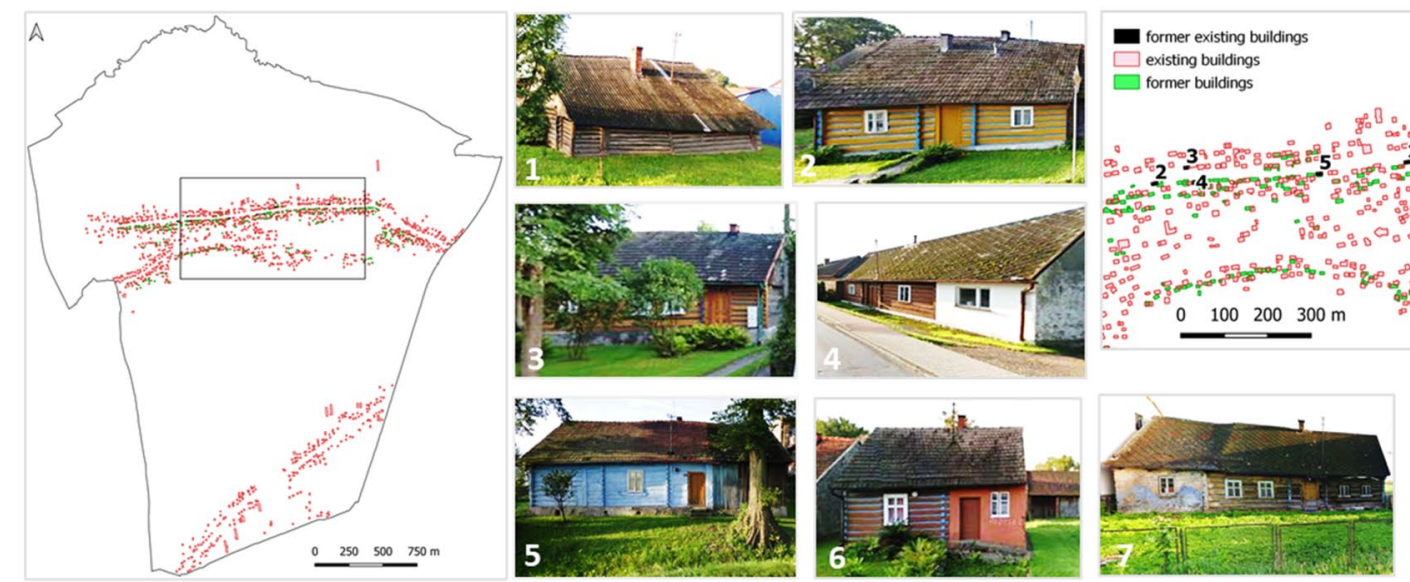

Figure 8. Analysis of historical and modern development overlap; identification of historical objects with examples of historical buildings in Kaszów identified using land structure persistence method.

\section{Discussion}

The empirical spatial arrangements evaluation method aims at identifying the persistence of landscape understood as traditional, in the context of rural cultural heritage.

The assessment requires an assumption that the analysed space has striped or patchwork layouts of plots with fields, baulks, ponds, meadows and forests in the landscape structure, which in geographic terms limits the method's applicability to agricultural areas in temperate Central and Eastern Europe.

Traditional landscapes preserved their character thanks to the low dynamics of changes in the past ${ }^{70}$. In general, the literature describes traditional agricultural landscapes as those where farming consumes low external resources and is dominated by relatively small (family) holdings ${ }^{21}$. In structural terms, these landscapes usually have smaller fields and components that reflect past ways of management, such as hedgerows or stone walls ${ }^{41}$. When classifying such landscapes, one should assess the persistence of land-cover types ${ }^{40}$ and persistence of land structure or field layout ${ }^{23,41}$. The degree of persistence of spatial arrangements helps determine the extent to which the landscapes hold cultural heritage and the level of impact of consecutive transformations. The proposed 
method can help identify traditional agricultural landscapes ${ }^{2,37,39}$ where the natural environment and farm structure demonstrate an evident mosaic layout. It narrows down the area for analysis by identifying sites with a significant potential for historical spatial arrangements and buildings that could be part of cultural heritage. An additional effect can be the indication of spatial units that were particularly resilient to changes in the landscape structure. In some cases resilience can originate from economic stagnation, as it was in case of Poland during the communist period. On the other hand, historical agricultural reforms in many Eastern Bloc countries irretrievably destroyed the spatial structure of land ${ }^{10}$. As economic growth often causes changes, periods of stagnation and stability tend to promote small-scale adaptation ${ }^{70}$. Sites resistant to transformation should be the focal point of institutions responsible for regional assistance and development.

The study has shown that the structure of the investigated area consists of small fields. It was determined, however, that further modifications have burdened the current sizes of plots and fields as well as their layout. Only part of the area was found to have a high degree of persistence of historical layouts from 1848 (see Fig. 7G). Only four per cent of the study area had the best, very high level of persistence of historical layouts, while $42 \%$ exhibited high persistence. This supports the conclusion that one should be particularly cautious when defining traditional historical landscapes in an area, which is consistent with findings by Renes ${ }^{1}$.

The assessment of rural development arrangement persistence was based on the building boundary persistence $^{55}$. It identified potential historical rural developments in the area. There were eight buildings identified that could date back to 1848 (see Fig. 7H).

The proposed methodology helps identify particular historical locations, enclaves of field systems that retained their unique historical spatial structure of the land, with the associated settlement structures in the agricultural landscape of Central and Eastern Europe. Moreover, the method is relatively simple to apply and very costeffective (economically justifiable).

The proposed method can monitor the current persistence in rural cultural landscapes in regular time intervals. Plenty of rural cultural landscapes face severe threats due to the intensification or abandonment ${ }^{21}$. Knowledge gained through the identification of homogeneous sets of spatial units and the determination of the persistence of local historical spatial arrangements can be applied to planning documents to facilitate adaptation and protection. Renes ${ }^{1}$ noted that an in-depth understanding of a complex history of landscapes could help transform heritage landscape management from the choice between protection or development to a more sophisticated process of change management. The data can further be used when implementing municipal development policies such as the promotion of tourism, protection, or repairs ${ }^{71}$.

\section{Conclusions}

The proposed methodology for determining the persistence of landscape structural layouts employs a GIS tool, intersect of land-cover type, agricultural land layout, and buildings persistence. Land arrangements were assessed with such parameters as the plot area, shape, or elongation and the main plot axis angle directly representing the spatial arrangement of the field layout (referred to in Polish literature as the patchwork). They aggregated the analysed components to identify spatial units exhibiting various degrees of persistence of rural historical spatial arrangements (low to very high). This quantitative approach to the landscape layout structure persistence has not been employed to date with the proposed methodological conditions.

Rural areas are currently under pressure from changes resulting from the introduction of extensive agricultural policies, changes in land use dictated by economic considerations and climate change. Structural transformations taking place in the rural space cause irreversible changes. The article attempts to define the components of cultural heritage related to the spatial structure of land in a comprehensive way. They were quantified and a method of empirical evaluation of landscape durability was proposed. This method allows us to identify places more resistant to transformation and those with greater cultural potential.

The proposed method can identify agricultural areas in Eastern and Central Europe isolated in terms of development that are characteristically located and have a specific local community with features characteristic to it. It is the place Solymosi ${ }^{2}$ indicated when investigating the impact of various factors on the preservation of cultural heritage.

The proposed tool can be used to monitor the degree of changes in the landscape layout structure when multiple time points are analysed as well. The method can also be applied to a shorter period for which maps with use or ownership structure are available, such as from the early twentieth century or after the Second World War.

Received: 24 June 2021; Accepted: 17 November 2021

Published online: 03 December 2021

\section{References}

1. Renes, H. Historic landscapes without history? A reconsideration of the concept of traditional landscapes. Rural Landsc. Soc. Environ. Hist. 2, 1-11 (2015).

2. Solymosi, K. Indicators for the identification of cultural landscape hotspots in Europe. Landsc. Res. 36, 3-18. https://doi.org/10. 1080/01426397.2010.530647 (2011).

3. Primdahl, J., Pinto-Correia, T. \& Pedroli, B. European landscapes in transition: implications for policy integration and landscape governance. EuroChoices 18, 18-23. https://doi.org/10.1111/1746-692x.12211 (2019).

4. Zomeni, M., Tzanopoulos, J. \& Pantis, J. D. Historical analysis of landscape change using remote sensing techniques: an explanatory tool for agricultural transformation in Greek rural areas. Landsc. Urban Plan. 86, 38-46. https://doi.org/10.1016/j.landurbplan. 2007.12.006 (2008).

5. O'Rourke, E. Changing identities, changing landscapes: human-land relations in transition in the Aspre, Roussillon. Ecumene 6, 29-50. https://doi.org/10.1191/096746099701556024 (1999).

6. Plieninger, T. et al. The driving forces of landscape change in Europe: a systematic review of the evidence. Land Use Policy 57, 204-214. https://doi.org/10.1016/j.landusepol.2016.04.040 (2016). 
7. Burgi, M., Hersperger, A. M. \& Schneeberger, N. Driving forces of landscape change-current and new directions. Landsc. Ecol. 19, 857-868. https://doi.org/10.1007/s10980-004-0245-8 (2004).

8. Hernik, J., Gawronski, K. \& Dixon-Gough, R. Social and economic conflicts between cultural landscapes and rural communities in the English and Polish systems. Land Use Policy 30, 800-813. https://doi.org/10.1016/j.landusepol.2012.06.006 (2013).

9. Bicik, I., Jelecek, L. \& Stepanek, V. Land-use changes and their social driving forces in Czechia in the 19th and 20th centuries. Land Use Policy 18, 65-73. https://doi.org/10.1016/s0264-8377(00)00047-8 (2001).

10. Banski, J. The consequences of changes of ownership for agricultural land use in Central European countries following the collapse of the Eastern Bloc. Land Use Policy 66, 120-130. https://doi.org/10.1016/j.landusepol.2017.04.045 (2017).

11. Connolly, C. Whose landscape, whose heritage? Landscape politics of "swiftlet farming' in a World Heritage City. Landsc. Res. 42, 307-320. https://doi.org/10.1080/01426397.2016.1267128 (2017).

12. Otero, I., Boada, M. \& Tabara, J. D. Social-ecological heritage and the conservation of Mediterranean landscapes under global change. A case study in Olzinelles (Catalonia). Land Use Policy 30, 25-37. https://doi.org/10.1016/j.landusepol.2012.02.005 (2013).

13. Snowball, J. D. \& Courtney, S. Cultural heritage routes in South Africa: effective tools for heritage conservation and local economic development?. Dev. South. Afr. 27, 563-576. https://doi.org/10.1080/0376835x.2010.508589 (2010).

14. Cultural Territorial Systems: Landscape and Cultural Heritage as a Key to Sustainable and Local Development in Eastern Europe Springer Geography (eds F. Rotondo, F. Selicato, V. Marin, \& J. L. Galdeano) 1-386 (2016).

15. Del Lungo, S., Sabia, C. A. \& Pacella, C. in Heritage as an Alternative Driver for Sustainable Development and Economic Recovery in South East Europe-Project See/B/0016/4.3/X Sagittarius Vol. 188 Procedia Social and Behavioral Sciences (ed V. Vasile) 95-102 (2015).

16. Boryczka, E. M., Michalak, J. \& Rzenca, P. Protection of valuable areas of local cultural heritage in sustainable development. Cultural parks in the Lodz Region. Ekonomia I Srodowisko-Econom. Environ. 1, 225-240 (2019).

17. Kozien, A. The principle of sustainable development as the basis for weighing the public interest and individual interest in the scope of the cultural heritage protection law in the European Union. Sustainability https://doi.org/10.3390/su13073985 (2021).

18. Shipley, R. \& Feick, R. A practical approach for evaluating cultural heritage landscapes: lessons from rural Ontario. Plan. Pract. Res. 24, 455-469. https://doi.org/10.1080/02697450903327113 (2009).

19. Scorza, F. et al. Conflicts between environmental protection and energy regeneration of the historic heritage in the case of the city of Matera: tools for assessing and dimensioning of sustainable energy action plans (SEAP). Comput. Sci. Appl. 10409, 527-539. https://doi.org/10.1007/978-3-319-62407-5_37 (2017).

20. Tweed, C. \& Sutherland, M. Built cultural heritage and sustainable urban development. Landsc. Urban Plan. 83, 62-69. https:// doi.org/10.1016/j.landurbplan.2007.05.008 (2007).

21. Tieskens, K. F. et al. Characterizing European cultural landscapes: accounting for structure, management intensity and value of agricultural and forest landscapes. Land Use Policy 62, 29-39. https://doi.org/10.1016/j.landusepol.2016.12.001 (2017).

22. Feuer, H. N., Van Assche, K., Hernik, J., Czesak, B. \& Rozycka-Czas, R. Evolution of place-based governance in the management of development dilemmas: long-term learning from Malopolska, Poland. J. Environ. Planning Manag. 64, 1312-1330. https://doi. org/10.1080/09640568.2020.1820314 (2021).

23. Benoit, M. et al. Landscape agronomy: a new field for addressing agricultural landscape dynamics. Landscape Ecol. 27, 1385-1394. https://doi.org/10.1007/s10980-012-9802-8 (2012).

24. (ECOVAST c/o Mrs Valerie CARTER (President), "Sherborne", Ingleden Park Road, Tenterden, Kent TN30 6NS, UK, 2006).

25. Antrop, M. Why landscapes of the past are important for the future. Landsc. Urban Plan. 70, 21-34. https://doi.org/10.1016/j.landu rbplan.2003.10.002 (2005).

26. Allen, R. C. Tracking the agricultural revolution in England. Econ. Hist. Rev. 52, 209-+. https://doi.org/10.1111/1468-0289.00123 (1999).

27. Vol. European Treaty Series-No. 176 (Council of Europe, Florence, 2000).

28. Palang, H. et al. Social landscape: ten years of planning "valuable landscapes" in Estonia. Land Use Policy 28, 19-25. https://doi. org/10.1016/j.landusepol.2010.04.004 (2011).

29. Solon, J. et al. Physico-geographical mesoregions of poland: verification and adjustment of boundaries on the basis of contemporary spatial data. Geogr. Pol. 91, 143-170. https://doi.org/10.7163/GPol.0115 (2018).

30. Ales, R. F., Martin, A., Ortega, F. \& Ales, E. E. Recent changes in landscape structure and function in a mediterranean region of Sw Spain (1950-1984). Landscape Ecol. 7, 3-18. https://doi.org/10.1007/bf02573953 (1992).

31. Stobbelaar, D. J. \& Pedroli, B. Perspectives on landscape identity: a conceptual challenge. Landsc. Res. 36, 321-339. https://doi.org/ $10.1080 / 01426397.2011 .564860(2011)$.

32. Chrastina, P., Hroncek, P., Gregorova, B. \& Zoncova, M. Land-use changes of historical rural landscape-heritage, protection, and sustainable ecotourism: case study of Slovak Exclave Civ (Piliscsev) in Komarom-Esztergom County (Hungary). Sustainability 12, 125. https://doi.org/10.3390/su12156048 (2020).

33. Antrop, M. The concept of traditional landscapes as a base for landscape evaluation and planning. The example of Flanders Region. Landsc. Urban Plan. 38, 105-117. https://doi.org/10.1016/s0169-2046(97)00027-3 (1997).

34. Fischer, J., Hartel, T. \& Kuemmerle, T. Conservation policy in traditional farming landscapes. Conserv. Lett. 5, 167-175. https:// doi.org/10.1111/j.1755-263X.2012.00227.x (2012).

35. Avriel-Avni, N., Rofe, Y. \& Scheinkman-Shachar, F. Spatial modeling of landscape values: discovering the boundaries of conflicts and identifying mutual benefits as a basis for land management. Soc. Nat. Resour. 34, 553-570. https://doi.org/10.1080/08941920. 2020.1850957 (2021).

36. Howley, P., Donoghue, C. O. \& Hynes, S. Exploring public preferences for traditional farming landscapes. Landsc. Urban Plan. 104, 66-74. https://doi.org/10.1016/j.landurbplan.2011.09.006 (2012).

37. Spulerova, J. et al. Developing a strategy for the protection of traditional agricultural landscapes based on a complex landscapeecological evaluation (the case of a mountain landscape in Slovakia). Moravian Geogr. Rep. 21, 15-26. https://doi.org/10.2478/ mgr-2013-0017 (2013).

38. Lieskovsky, J. et al. Factors affecting the persistence of traditional agricultural landscapes in Slovakia during the collectivization of agriculture. Landsc. Ecol. 29, 867-877. https://doi.org/10.1007/s10980-014-0023-1 (2014).

39. Patru-Stupariu, I., Tudor, C. A., Stupariu, M. S., Buttler, A. \& Peringer, A. Landscape persistence and stakeholder perspectives: the case of Romania's Carpathians. Appl. Geogr. 69, 87-98. https://doi.org/10.1016/j.apgeog.2015.07.015 (2016).

40. Lieskovsky, J. \& Burgi, M. Persistence in cultural landscapes: a pan-European analysis. Reg. Environ. Change 18, 175-187. https:// doi.org/10.1007/s10113-017-1192-7 (2018).

41. van der Zanden, E. H., Verburg, P. H. \& Mucher, C. A. Modelling the spatial distribution of linear landscape elements in Europe. Ecol. Ind. 27, 125-136. https://doi.org/10.1016/j.ecolind.2012.12.002 (2013).

42. Jepsen, M. R. et al. Transitions in European land-management regimes between 1800 and 2010. Land Use Policy 49, 53-64. https:// doi.org/10.1016/j.landusepol.2015.07.003 (2015).

43. van Zanten, B. T., Verburg, P. H., Koetse, M. J. \& van Beukering, P. J. H. Preferences for European agrarian landscapes: a metaanalysis of case studies. Landsc. Urban Plan. 132, 89-101. https://doi.org/10.1016/j.landurbplan.2014.08.012 (2014).

44. Banski, J. \& Mazur, M. Classification of rural areas in Poland as an instrument of territorial policy. Land Use Policy 54, 1-17. https:// doi.org/10.1016/j.landusepol.2016.02.005 (2016). 
45. Plit, J. \& Myga-Piatek, U. The degree of landscape openness as a manifestation of cultural metamorphose. Quaestiones Geographicae 33, 145-154. https://doi.org/10.2478/quageo-2014-0036 (2014).

46. Geri, F., Amici, V. \& Rocchini, D. Human activity impact on the heterogeneity of a Mediterranean landscape. Appl. Geogr. 30, 370-379. https://doi.org/10.1016/j.apgeog.2009.10.006 (2010).

47. Serra, P., Pons, X. \& Sauri, D. Land-cover and land-use change in a Mediterranean landscape: a spatial analysis of driving forces integrating biophysical and human factors. Appl. Geogr. 28, 189-209. https://doi.org/10.1016/j.apgeog.2008.02.001 (2008).

48. Su, S. L., Jiang, Z. L., Zhang, Q. \& Zhang, Y. A. Transformation of agricultural landscapes under rapid urbanization: a threat to sustainability in Hang-Jia-Hu region, China. Appl. Geogr. 31, 439-449. https://doi.org/10.1016/j.apgeog.2010.10.008 (2011).

49. Baessler, C. \& Klotz, S. Effects of changes in agricultural land-use on landscape structure and arable weed vegetation over the last 50 years. Agr. Ecosyst. Environ. 115, 43-50. https://doi.org/10.1016/j.agee.2005.12.007 (2006).

50. Simensen, T., Halvorsen, R. \& Erikstad, L. Methods for landscape characterisation and mapping: a systematic review. Land Use Policy 75, 557-569. https://doi.org/10.1016/j.landusepol.2018.04.022 (2018).

51. Li, E. J., Endter-Wada, J. \& Li, S. J. Dynamics of Utah's agricultural landscapes in response to urbanization: a comparison between irrigated and non-irrigated agricultural lands. Appl. Geogr. 105, 58-72. https://doi.org/10.1016/j.apgeog.2019.02.006 (2019).

52. Cushman, S. A., McGariyal, K. \& Neel, M. C. Parsimony in landscape metrics: strength, universality, and consistency. Ecol. Ind. 8, 691-703. https://doi.org/10.1016/j.ecolind.2007.12.002 (2008).

53. Kim, K. H. \& Pauleit, S. Landscape character, biodiversity and land use planning: The case of Kwangju City Region, South Korea. Land Use Policy 24, 264-274. https://doi.org/10.1016/j.landusepol.2005.12.001 (2007).

54. Aburas, M. M., Ho, Y. M., Ramli, M. F. \& Ashaari, Z. H. Monitoring and assessment of urban growth patterns using spatio-temporal built-up area analysis. Environ. Monit. Assess. 190, 12369. https://doi.org/10.1007/s10661-018-6522-9 (2018).

55. Torreggiani, D. et al. TRuLAn: a high-resolution method for multi-time analysis of traditional rural landscapes and its application in Emilia-Romagna, Italy. Landsc. Urban Plan. 124, 93-103. https://doi.org/10.1016/j.landurbplan.2014.01.011 (2014).

56. Stanfield, B. J., Bliss, J. C. \& Spies, T. A. Land ownership and landscape structure: a spatial analysis of sixty-six Oregon (USA) Coast Range watersheds. Landsc. Ecol. 17, 685-697. https://doi.org/10.1023/a:1022977614403 (2002).

57. Sklenicka, P. \& Salek, M. Ownership and soil quality as sources of agricultural land fragmentation in highly fragmented ownership patterns. Landsc. Ecol. 23, 299-311. https://doi.org/10.1007/s10980-007-9185-4 (2008).

58. Zhao, H. Z. et al. Incorporating spatio-temporal connectivity for prioritized conservation of individual habitat patches in a dynamic landscape. Ecol. Indic. 124, 1029. https://doi.org/10.1016/j.ecolind.2021.107414 (2021).

59. Postek, P., Len, P. \& Strek, Z. The proposed indicator of fragmentation of agricultural land. Ecol. Ind. 103, 581-588. https://doi. org/10.1016/j.ecolind.2019.04.023 (2019).

60. Gniadek, J., Janus, J. \& Bacior, S. The influence of land consolidation works on the efficiency of the production process. Acta Sci. Pol. Form. Circum. 16, 85-100. https://doi.org/10.15576/asp.fc/2017.16.4.85 (2017).

61. Krummel, J. R., Gardner, R. H., Sugihara, G., Oneill, R. V. \& Coleman, P. R. Landscape patterns in a disturbed environment. Oikos 48, 321-324. https://doi.org/10.2307/3565520 (1987).

62. Lausch, A. et al. Understanding and quantifying landscape structure-a review on relevant process characteristics, data models and landscape metrics. Ecol. Model. 295, 31-41. https://doi.org/10.1016/j.ecolmodel.2014.08.018 (2015).

63. Bieling, C., Plieninger, T. \& Schaich, H. Patterns and causes of land change: empirical results and conceptual considerations derived from a case study in the Swabian Alb, Germany. Land Use Policy 35, 192-203. https://doi.org/10.1016/j.landusepol.2013.05.012 (2013).

64. Haase, D., Walz, U., Neubert, M. \& Rosenberg, M. Changes to Central European landscapes-analysing historical maps to approach current environmental issues, examples from Saxony, Central Germany. Land Use Policy 24, 248-263. https://doi.org/10.1016/j. landusepol.2005.09.003 (2007).

65. Schulp, C. J. E., Levers, C., Kuemmerle, T., Tieskens, K. F. \& Verburg, P. H. Mapping and modelling past and future land use change in Europe's cultural landscapes. Land Use Policy 80, 332-344. https://doi.org/10.1016/j.landusepol.2018.04.030 (2019).

66. Frajer, J. \& Fiedor, D. A historical curiosity or a source of accurate spatial information on historical land use? The issue of accuracy of old cadastres in the example of Josephian Cadastre from the Habsburg Empire. Land Use Policy 100, 1039. https://doi.org/10. 1016/j.landusepol.2020.104937 (2021).

67. Hernik, J. et al. The evolution of cadastral systems in Austria and Galicia (Poland): different approaches to a similar system from a common beginning. Cartogr. J. 57, 97-112. https://doi.org/10.1080/00087041.2018.1534344 (2020).

68. Janes, A. Making maps of records: what cartography can teach us about archival description. Arch. Rec. J. Arch. Rec. Assoc. 42, 95-118. https://doi.org/10.1080/23257962.2021.1873118 (2021).

69. Zachariasz, A. Beginnings of landscape architecture in Poland. Landsc. Archit. Art 13, 115-127. https://doi.org/10.22616/j.landa rchart.2018.13.13 (2018).

70. Plieninger, T., Hochtl, F. \& Spek, T. Traditional land-use and nature conservation in European rural landscapes. Environ. Sci. Policy 9, 317-321. https://doi.org/10.1016/j.envsci.2006.03.001 (2006).

71. Sanchez, M. L., Cabrera, A. T. \& Del Pulgar, M. L. G. Guidelines from the heritage field for the integration of landscape and heritage planning: a systematic literature review. Landsc. Urban Plan. https://doi.org/10.1016/j.landurbplan.2020.103931 (2020).

\section{Author contributions}

B.P., M.D. and S.B. wrote the main manuscript text and reviewed the manuscript. B.P. prepared the figures.

\section{Funding}

Funding was provided by Polish National Agency for Academic Exchange(Grant No. PPI/ APM/2018/1/00010/U/001).

\section{Competing interests}

The authors declare no competing interests.

\section{Additional information}

Correspondence and requests for materials should be addressed to B.P.

Reprints and permissions information is available at www.nature.com/reprints.

Publisher's note Springer Nature remains neutral with regard to jurisdictional claims in published maps and institutional affiliations. 
(c) (i) Open Access This article is licensed under a Creative Commons Attribution 4.0 International cc) License, which permits use, sharing, adaptation, distribution and reproduction in any medium or format, as long as you give appropriate credit to the original author(s) and the source, provide a link to the Creative Commons licence, and indicate if changes were made. The images or other third party material in this article are included in the article's Creative Commons licence, unless indicated otherwise in a credit line to the material. If material is not included in the article's Creative Commons licence and your intended use is not permitted by statutory regulation or exceeds the permitted use, you will need to obtain permission directly from the copyright holder. To view a copy of this licence, visit http://creativecommons.org/licenses/by/4.0/.

(C) The Author(s) 2021 